\title{
Effectiveness of Piriformis Stretching and Intermittent Lumbar Traction along with Spinal Extension Exercises in Lumbar Disc Herniation: Comparative Study
}

\author{
Rituraj Verma ${ }^{1}$, Taruna Verma ${ }^{2}$, Vikas Sharma ${ }^{3}$, Yash Pratap ${ }^{4}$, Sanghamitra Jena ${ }^{5}$, Sajjad Alam ${ }^{6}$ \\ ${ }^{1}$ Associate Prof., HOD Physiotherapy dept, Galgotias University, ${ }^{2}$ Assistant Prof., Galgotias University, ${ }^{3}$ Assistant \\ Prof., Galgotias University, ${ }^{4}$ Associate Prof., Galgotias University, ${ }^{5}$ Assistant Prof., Galgotias University, \\ ${ }^{6}$ Associate Prof., Galgotias University
}

\begin{abstract}
Objective: To compare the effect of Piriformis Stretching and Intermittent Lumbar Traction along with Spinal Extension Exercises in Lumbar Disc Herniation.

Sample: Total 30 subjects were taken for the study.

Design: Pre-test \& post-test design.

Method: 30 subjects fulfilling selection criteria participated in the study. All of them were told about the procedure of study. All their queries were answered satisfactorily, and informed consent was taken from them. Intermittent lumbar traction, piriformis stretching, and spinal extension exercises were given to the participants. In the beginning of treatment, they were given VAS, Roland- Morris Low Back Pain and Disability Questionnaire and Oswestry Low Back Pain Disability Questionnaire. They were asked to fill these questionnaires. After 1 week protocol of treatment they were again told to fill these outcome measures. The participants were selected for the inclusion and exclusion criteria of the study. The patient consent was taken to be comfortable and relaxed.
\end{abstract}

Conclusion: Study suggests that Piriformis Stretching along with Spinal Extension Exercises plays a significant role in reducing pain and disability as compared to traction along with Spinal Extension Exercises. By using Piriformis Stretching, in a short period of time, patients are able to carry out functions of daily living smoothly.

Keywords: Pain, Disability, Lumbar disc herniation (LDH), tumor necrosis factor (TNF).

\section{Introduction}

Herniated disc is a musculoskeletal disorder responsible for sciatica and occurs due to rupture of the annulus fibrosus, following the displacement of the central mass of the intervertebral disc into thedorsalordorso-

\section{Corresponding Author:}

Dr. Rituraj Verma

Associate professor, Galgotias University

Address: 184/14, Vasundhara, Ghaziabad

e-mail: rituraj.verma@galgotiasuniversity.edu.in

Mobile No.: 9953434095 lateraldiscspaces ${ }^{1}$. Lumbar disc herniations are believed to result from annular degeneration that leads to a weakening of the annulus fibrosus, leaving the disc susceptible to annular fissuring and tearing ${ }^{2}$. Lumbar disc resolves their symptoms without substantial medical intervention ${ }^{3}$. It mainly affects individual between 30 $\& 50$ years of age ${ }^{4}$. Furthermore, the complete natural history oft his disorder is inadequately described, although a variety of anecdotal as well as level 4-5 evidence exists, suggesting that $90 \%$ of been estimated to be attack is 37 and in $76 \%$ of cases there is prior history of low back pain within the previous ten years ${ }^{5}$. Lumbar disc herniation is a common condition that frequently affects the spine in young and middle age patient ${ }^{6}$. 
Symptomatic herniation of the nucleus pulposus in the lumbar spine affects $1 \%-2 \%$ of the general population sometime during their lives ${ }^{7}$. Symptomatic herniation of the nucleus pulposus is most prevalent in men during the fourth and fifth decades of life ${ }^{8}$. Although the majority of disc herniations occur at the L2-L3, L4/5 or L5/S1 level ${ }^{9}$. The majority of spinal disc herniation cases occur in the lumbar region (95\% in L4- L5 orL5-S1) ${ }^{10}$.

Methodology: A total number of 30 subjects were included fort he study, who fulfilling inclusion and exclusion criteria volunteered to take part in the study. Subjects were recruited from Divine Physiotherapy Clinic, Vasundhara, consent statement was taken from the subjects to be apart of the study. The Demographic data of the subjects were analyzed by pre-post paired, unpaired t-test, by using SPSS14.

Inclusion Criteria: Both males and females of age group 35-45 years, both males and females having Lumbar disc herniation (L4-L5 level), Low back pain involving lower extremities, Sciatica.

Exclusion Criteria: Mentally challenged, Pregnancy, Children and old age people, Congenital pathology of lumbar spine, Surgery of lumbar spine, Infectious disease, Cervical and thoracic herniated disc

Outcome Measures: 1) Visual Analogue Scale, 0-10 grades 2) The Roland - Morris Low Back Pain and Disability, having 24 Questionnaire 3) Oswestry Low Back Pain Disability having 10 statement Questionnaire, includes, pain intensity, personal care (washing, dressing etc.), lifting, walking, sitting, standing, sleeping, sex life, social life and travelling.

\section{Methodology}

30 subjects fulfilling selection criteria participated in the study. All of them were told about the procedure of study. All their queries were answered satisfactorily, and informed consent was taken from them. Intermittent lumbar traction, piriformis stretching, and spinal extension exercises were given to the participants. In the beginning of treatment, they were given VAS, RolandMorris Low Back Pain and Disability Questionnaire and Oswestry Low Back Pain Disability Questionnaire. They were asked to fill these questionnaires. After 1-week protocol of treatment they were again told to fill these outcome measures. Data was collected in the data collection form. All the patients were asked to perform spinal extension exercises (dog-bird,Cat- cow, Half cobra) 10 second hold and 10 repetitions once a day for one week. Intermittent lumbar traction was given to 15 subjects for 15 minutes once a day for one week, Piriformis stretching were given to another 15 subjects with 30 second hold and 4 repetitions once a day for oneweek.

Data Analysis: To analyze the effect of Piriformis Stretching and Intermittent Lumbar Traction on total 30 (15 PS and 15 ILT) subjects, post scores \& post-post scores of pain were analyzed by using Mean, Standard Deviation and t-test. Paired t- test was used to find out any significant differences between pre-post test and unpaired t-test was used between post-post test of pain to assess which intervention significantly reduce the pain for assigned duration and frequency.

Comparision of Visual Analogue Scale (Piriformis Stretching) between Pre and Post Test:

\begin{tabular}{|l|l|l|c|c|c|c|c|c|}
\hline Variable & Group & Treatment & N & Mean & S. D. & $\begin{array}{c}\text { Standard Error } \\
\text { Mean }\end{array}$ & D.F & t-value \\
\hline $\begin{array}{l}\text { Visual Analogue } \\
\text { Scale }\end{array}$ & Pre-Test & \multirow{2}{*}{ Piriformis Stretching } & 15 & 7.26 & .59 & .15 & \multirow{2}{*}{$15.19 *$} \\
\cline { 2 - 7 } & Post-Test & & 15 & 2.86 & 1.06 & .27 & 14 \\
\hline
\end{tabular}

*Significant at 0.01 level df $=14$, At $0.01 \mathrm{t}$-value of the Table is 2.97

Comparision of Visual Analogue Scale (Intermittent Lumbar Traction) between Pre and Post Test:

\begin{tabular}{|c|c|c|c|c|c|c|c|c|}
\hline Variable & Group & Treatment & $\mathbf{N}$ & Mean & S.D. & $\begin{array}{c}\text { Standard Error } \\
\text { Mean }\end{array}$ & DF & t-value \\
\hline \multirow{2}{*}{$\begin{array}{l}\text { Visual Analogue } \\
\text { Scale }\end{array}$} & Pre-Test & \multirow{2}{*}{$\begin{array}{l}\text { Intermittent } \\
\text { Lumbar Traction }\end{array}$} & 15 & 7.26 & .88 & .22 & \multirow{2}{*}{14} & \multirow{2}{*}{$12.58^{*}$} \\
\hline & Post-Test & & 15 & 4.46 & .91 & .23 & & \\
\hline
\end{tabular}

*Significant at 0.01 level $\mathrm{df}=14$, At $0.01 \mathrm{t}$-value of the Table is 2.97 
Comparision of Visual Analogue Scale between Post Test (Piriformis Stretching) and Post Test (Intermittent Lumbar Traction):

\begin{tabular}{|c|c|c|c|c|c|c|c|c|}
\hline Variable & Group & Treatment & $\mathbf{N}$ & Mean & S. D. & $\begin{array}{c}\text { Standard } \\
\text { Error Mean }\end{array}$ & D.F. & t-value \\
\hline \multirow{2}{*}{$\begin{array}{l}\text { Visual Analogue } \\
\text { Scale }\end{array}$} & Post-Test & Piriformis Stretching & 15 & 2.86 & 1.06 & .27 & \multirow[b]{2}{*}{28} & \multirow[b]{2}{*}{$4.42 *$} \\
\hline & Post-Test & $\begin{array}{l}\text { Intermittent Lumbar } \\
\text { Traction }\end{array}$ & 15 & 4.46 & .91 & .23 & & \\
\hline
\end{tabular}

*Significant at 0.01 level df $=28$, At $0.01 \mathrm{t}$-value of the Table is 2.76

Comparision of Oswestry between Post Test Piriformis Stretching) and Post Test (Intermittent Lumbartraction):

\begin{tabular}{|c|c|c|c|c|c|c|c|c|}
\hline Variable & Group & Treatment & $\mathbf{N}$ & Mean & S. D. & $\begin{array}{c}\text { Standard Error } \\
\text { Mean }\end{array}$ & D.F & t-value \\
\hline \multirow{2}{*}{ Oswestry } & Post-Test & Piriformis Stretching & 15 & 29.68 & 8.39 & 2.16 & \multirow{2}{*}{28} & \multirow{2}{*}{$1.57 * *$} \\
\hline & Post-Test & Intermittent Lumbar Traction & 15 & 35.65 & 12.07 & 3.11 & & \\
\hline
\end{tabular}

** Not Significant at 0.01 level df $=28$, At $0.01 \mathrm{t}$-value of the Table is 2.76

Comparision of Roland Morris Back Pain and Disability (Intermittent Lumbar Traction) Pre and Posttest:

\begin{tabular}{|l|l|l|c|c|c|c|c|c|}
\hline Variable & Group & Treatment & N & Mean & S. D. & $\begin{array}{c}\text { Standard Error } \\
\text { Mean }\end{array}$ & DF & t-value \\
\hline \multirow{2}{*}{$\begin{array}{l}\text { Roland Morris Back } \\
\text { Pain and Disability }\end{array}$} & Pre-Test & Intermittent Lumbar & 15 & 19.46 & 2.89 & .74 & \multirow{2}{*}{14} \\
\cline { 2 - 9 } & Pract-Test & Tran & 15 & 9.60 & 1.29 & .33 & 14 \\
\hline
\end{tabular}

*Significant at 0.01 level $\mathrm{df}=14$, At $0.01 \mathrm{t}$-value of the Table is 2.97

Comparision of Roland Morris Back Pain and Disability between Post Test (Piriformis Stretching) and Post Test (Intermittent Lumbar Traction):

\begin{tabular}{|c|c|c|c|c|c|c|c|c|}
\hline Variable & Group & Treatment & $\mathbf{N}$ & Mean & S. D. & $\begin{array}{c}\text { Standard } \\
\text { Error Mean }\end{array}$ & D.F & t-value \\
\hline \multirow{2}{*}{$\begin{array}{l}\text { Roland Morris Back } \\
\text { Pain and Disability }\end{array}$} & Post-Test & Piriformis Stretching & 15 & 5.00 & 2.00 & .51 & \multirow{2}{*}{28} & \multirow{2}{*}{$7.47 *$} \\
\hline & Post-Test & Intermittent Lumbar Traction & 15 & 9.60 & 1.29 & .33 & & \\
\hline
\end{tabular}

*Significant at 0.01 level df $=28$, At $0.01 \mathrm{t}$-value of the Table is 2.76

\section{Result}

The results of this study support that Piriformis stretching will be more effective and significant in reducing pain and disability (due to $L D H$ ) than Intermittent Lumbar Traction.

Future Scope and Research: Present study was limited to 35-45 age group. Further research examining the effects of both PS and ILT on individuals in younger and older age groups would be of interest. Future research must include a follow-up of at least 15 days/16 days to check the short term/long term effects of PS and ILT.

\section{Conclusion}

Study suggests that Piriformis Stretching along with Spinal Extension Exercises plays a significant role in reducing pain and disability as compared to traction along with Spinal Extension Exercises.

Ethical Clearance: Prior Patient consent form was taken.

Source of Funding: Self

Conflict of Interest: Nil 


\section{References}

1. Barros Filho, TEP, Basile Junior R, Coluna. Vertebral: diagostico etratamento das principais patologias. Sao Paulo: Savier,1995.

2. Saal JA. Natural history and non-operative treatment of lumbar disc herniation. Spine. 1996; 21(24suppl): 2S-9S.

3. Schoenfeld AJ, Weiner BK et al. Treatment of lumbar disc herniation. International Journal of General Medicine.2010;3:209-214.

4. Garrido E. Lumbar disc herniation in the pediatric patient. Neurosurg clin N Am.1993;4(1):149-52.

5. BellGR, Rothman RH. The conservative treatment of sciatica. Spine (PhilePa 1976)1984;9(1):54-6.

6. Anderson PA, McCormickPC et al. Randomized controlled trials of the treatment of lumbar disc herniation. J Am Acad Orthop Surg. 2008;16:566573.

7. Deyo RA, Tsui-wu YJ. Descriptive epidemiology of low back pain and its related medical care in the United States. Spine(Phila Pa 1976).1987;12:2648.

8. Boden SD, Davis DO, Dina TS, Patronas NJ, Wiesel SW. Abnormal magnetic resonances cans of the lumbar spine in asymptomatic subjects. Aprospective investigation. J Bone Joint Surg Am. 1990;72:403-8.

9. Frymoyer JW. Back pain \& sciatica. N Eng/J Med. 1988;318:291-300. 10) Krishna V. Lumbar disc herniation. Orthopaedic Muscul Sys 1.2012;1:101.
Medico-legal Update, January-March 2021, Vol. 21, No. 1

10. Atlas SJ, Chang Y, Kammann E, Keller RB, Deyo RA, Singer DE. Long-term disability and return to work among patients who have a herniated lumbar disc: the effect of disability compensation. J Bone Joint Surg Am. 2000;82(1):4-15.

11. Matsui H, Kanamori M, Ishihara H, Yudoh K, Naruse $\mathrm{Y}$, Tsuji H. Familial predisposition for lumbar degenerative disc disease. A case-control study. Spine (Phila Pa 1976). 1998;23(9):1029-34.

12. Choi G, Raiturker PP, Kim MJ, Chung DJ, Chae YS, Lee SH. The effect of early isolated lumbar extension exercise program for patients with herniated disc undergoing lumbar discectomy. Neurosurgery.

13. Nachemson AL. Instability of the lumbar spine. Pathology, treatment, and clinical evaluation. Neurosurg Clin N Am 1991;2:785-90.

14. Hahne AJ, Ford JJ. Functional restoration for a chronic lumbar disk extrusion with associated radiculopathy. Phys Ther 2006;86:1668-80.

15. Weber $\mathrm{H}$. The natural history of disc herniation and the influence of intervention. Spine (Phila Pa 1976) 1994;19:2234-8.

16. Svensson GL, Wendt GK, Thomee R. Evaluation of a structured physiotherapy treatment model for patients with lumbar disc herniation. J Rehabil Med 2014;46:234-46.

17. Kalb S, Martirosyan NL, Kalani MYS, Broc GG, Theodore N. Genetics of the degenerated intervertebral disc. World Neurosurg. 2012;77(34):491-501. 